\title{
Successful epidural anaesthesia for a patient with Takayasu's arteritis presenting for Caesarean section
}

Yaakov Beilin MD, Howard Bernstein MD

The management of a 24-yr-old parturient with Takayasu's arteritis (TA) presenting at term for Caesarean section is discussed. The best anaesthetic management for the patient with $T A$ is controversial, but avoiding regional anaesthesia has been suggested by some authors because of the risk of hypotension and the subsequent need for vasopressors. We report the use of regional anaesthesia in a term parturient with severe TA undergoing Caesarean section. Anaesthesia was provided with chloroprocaine $3 \%$, via a lumbar epidural catheter. The initial doses of $60 \mathrm{mg}$ and $150 \mathrm{mg}$ were followed by a decrease in BP (from $110 / 70$ to 70/40) which was corrected with iv fluids and ephedrine $25 \mathrm{mg}$. Additional doses of chloroprocaine, 150 and 90 $m g$, were uneventful. It is concluded that an epidural can be made in safety to provide anaesthesia for Caesarean section in patients with $T A$.

On discute la conduite de l'anesthésique chez une patiente de 24 ans présentant une artérite de Takayasu (AT) programmée pour une césarienne à terme. La meilleure technique d'anesthésie chez ces patients est controversée, mais certains auteurs suggèrent d'éviter l'anesthésie régionale à cause du risque dhypotension et de la nécessité consécutive de vasopresseurs. Nous rapportons l'administration d'une anesthésie régionale à une patiente sérieusement atteinte de AT pour une césarienne à terme. L'anesthésie a été réalisée avec de la chloroprocaïne $3 \%$ par un cathéter épidural lombaire. Les doses initiale de $60 \mathrm{mg}$

\section{Key words}

ANAESTHESIA: obstetrical;

ANAESTHETIC TECHNIQUES: epidural;

COMPLICATIONS: Takayasu's arteritis, pregnancy.

From the Department of Anesthesia, The Mount Sinai Medical Center, Department of Anesthesiology, Box 1010, New York.

Address correspondence to: Dr. Yaakov Beilin, Department of Anesthesiology, The Mount Sinai Medical Center, One Gustave L. Levy Place, Box 1010, New York, NY 10029, (212) 241-7475.

Accepted for publication 29th August, 1992. et de $150 \mathrm{mg}$ entrainèrent une chute de pression artérielle (de $110 / 70$ à 70/40) qui a été traité par l'administration de liquides iv et de léphédrine $25 \mathrm{mg}$. Des doses additionnelles de chloroprocaïne, 150 et $90 \mathrm{mg}$, ont été administrées sans problèmes. On conclut que l'anesthésie épidurale peut être administrée sans danger pour réaliser l'anesthésie lors d'un césarienne chez une patiente atteintede $A T$.

Takayasu's arteritis (TA), also known as pulseless disease, is a rare type of aortic arch syndrome which primarily affects young women of Oriental or Asian descent. ${ }^{1.5}$ The parturient with severe TA presents a challenge to both the obstetrician and the anaesthetist. Blood pressure control is of paramount importance since patient's with TA can have arterial aneurysms and cerebral dysfunction from carotid occlusion. General anaesthesia has the advantage over regional anaesthesia because one can avoid the sympathectomy and subsequent hypotension induced during regional anaesthesia. However, regional anaesthesia, with an awake patient, is the easiest way to monitor cerebral function and is the preferred technique in the parturient. This report describes the clinical course of a parturient with severe TA in which a regional anaesthetic was successfully utilized for a Caesarean section.

\section{Case report}

A 24-yr-old hispanic woman, $70 \mathrm{~kg}$ and $167 \mathrm{~cm}$, para 1 , with a diagnosis of TA made in 1982, was admitted for elective Caesarean section. Initially, the patient presented with diffuse abdominal pain, nausea and vomiting and a pulseless left upper extremity. The diagnosis was made after investigation which included an erythrocyte sedimentation rate (ESR) of $110 \mathrm{~mm} \times \mathrm{hr}^{-1}$ and a CT scan which revealed alternating areas of stenosis and dilation in the aortic arch and left subclavian artery. She was treated for three years with prednisone, $80 \mathrm{mg}$ per day, and coumadin sufficient to maintain her prothrombin time at 1.5 times normal. After this course of treatment her disease went into remission and all medications were stopped. Repeat CT scan in 1986 revealed aneu- 
rysms involving her aortic arch, left subclavian artery, thoracic aorta, abdominal aorta and renal arteries. The largest aneurysms were of the abdominal aorta and thoracic aorta, which measured $4.5 \mathrm{~cm}$ and $4.0 \mathrm{~cm}$ respectively. There was no involvement of the right subclavian artery. Since 1986, blood pressure, measured in her right arm, ranged from $80-90 / 40-50 \mathrm{mmHg}$.

Physical examination prior to delivery showed absent pulses in the left upper extremity and decreased carotid pulses bilaterally. Pulses in the right upper extremity were normal. Blood pressure, throughout pregnancy, measured in the right arm ranged from $110-120 / 70-80 \mathrm{mmHg}$. There was no proteinuria or oedema. Exercise tolerance was good, and, thus she appeared to have normal ventricular function. The patient had no complaints of shortness of breath and her lung pulmonary examination was completely normal. There were no signs of decreased cerebral perfusion such as dizziness, fatigue or syncopal episodes associated with movement of her neck.

Preoperative laboratory findings included a normal ESR, BUN, creatinine, PT, PTT and electrocardiogram (ECG).

Sodium citrate $0.3 \mathrm{M} 30 \mathrm{ml}$ po was administered for premedication. A 14-gauge intravenous $i v$ catheter was introduced in her right hand and $1500 \mathrm{ml}$ PlasmalyteA was infused over $15 \mathrm{~min}$. Blood pressure was monitored by oscillometry in the right and left arms and right thigh. Additional monitors consisted of an ECG, leads II and $V_{5}$, a pulse oximeter on her right index finger and a fetal heart monitor. Left uterine displacement was maintained throughout the procedure. The blood pressures in the right arm and the right thigh correlated within $10 \%$. The systolic blood pressure ranged from 110 to $120 \mathrm{mmHg}$ and the diastolic pressure ranged from 70 to $80 \mathrm{mmHg}$. Blood pressure in the left arm was consistently less than in the right with systolic pressures of 70 to $80 \mathrm{mmHg}$ and diastolic pressures of 30 to 40 mmHg. Left arm blood pressure was not considered accurate and was not used for monitoring. The ECG was unremarkable and the pulse oximeter displayed a normal wave form with a saturation of $98-100 \%$ on room air. Urine output was monitored with a foley catheter and remained greater than $1 \mathrm{ml} \cdot \mathrm{kg}^{-1} \cdot \mathrm{hr}^{-1}$ throughout the procedure.

A continuous lumbar epidural was placed without difficulty at the $\mathrm{L}_{3}-\mathrm{L}_{4}$ interspace. Two $\mathrm{ml}$ chloroprocaine $3 \%$ were administered through the epidural catheter to rule out subarachnoid or intravenous placement of the epidural catheter. After ten minutes an additional $5 \mathrm{ml}$ chloroprocaine $3 \%$ were administered to initiate the epidural block. This dose led to a decrease in blood pressure from $110 / 70 \mathrm{mmHg}$ to $70 / 40 \mathrm{mmHg}$ with an increase in heart rate from 80 to $120 \mathrm{bpm}$. The patient complained of nausea and felt light headed. An additional $1500 \mathrm{ml}$ of Plasmalyte-A were infused and ephedrine $25 \mathrm{mg}$ was administered $i$ in $5 \mathrm{mg}$ increments to restore blood pressure. Two additional doses of chloroprocaine $3 \%, 5 \mathrm{ml}$ and $3 \mathrm{ml}$, were administered to achieve a $T_{4}$ level of block. The blood pressure and heart rate remained stable and a Caesarean section was begun. A baby girl with Apgar scores of nine at both one and five minutes was delivered. The patient received $4 \mathrm{mg}$ morphine sulphate via the epidural catheter for postoperative pain relief. The balance of her hospitalization was uneventful and the patient was discharged home five days later.

\section{Discussion}

Takayasu's arteritis, a disease of unknown aetiology, is a chronic progressive obstructive arteritis. Clinical feature of TA are varied, owing to the differences in the site and extent of involvement of the aorta and its branches. The most common sites affected are the aortic arch and its branches, the descending thoracic aorta, the thoracoabdominal aorta, and rarely the aortic bifurcation. ${ }^{7}$ Early symptoms include fever, malaise, weight loss, abdominal pain and a high ESR. Progression of the disease may be marked by aneurysmal dilatation of the affected arteries. The disease is often fatal, usually from cerebral ischaemia or heart failure. ${ }^{6}$

Blood pressure changes during labour are greater in the parturient with TA than in healthy patients. Therefore, the reasons for Caesarean section in the patient with TA depend both on obstetrical indications and on the severity of the disease. ${ }^{8}$ Since this patient had a severe form of TA as manifested by multiple aortic aneurysms, the decision was made jointly by the anaesthetists and the obstetricians to avoid the risk of aneurysmal rupture and perform an elective Caesarean section.

Accurate blood pressure monitoring, always a concern to the anaesthetist, is even more crucial in the patient with TA. Increases in blood pressure can cause rupture of the aneurysms and decreases in blood pressure can lead to cerebral ischaemia. However, this goal is not always easily achieved since typically these patients have pulseless upper extremities. ${ }^{4-6}$

Obtaining reliable blood pressures was not a problem in this patient since she had good pulses in her right arm and CT scan did not show any evidence of right upper extremity involvement. Furthermore, blood pressures obtained in her right arm correlated with those obtained in her right thigh which is known to reflect central blood pressures accurately. ${ }^{9}$ We opted not to place an arterial line in the patient because the blood pressure in the upper extremity was easily attainable and thus inflicting arterial trauma in a patient with a diffuse arteritis was not justified. 
Although left uterine displacement was implemented, prehydration given and tests for both intrathecal and intravascular injection performed, the patient's blood pressure decreased considerably after only $7 \mathrm{ml}$ chloroprocaine $3 \%$. Patients with TA may not tolerate acute decreases in preload since the diffuse arteritis leads to stenotic and non-compliant vessels which interferes with compensatory mechanisms. The presence of stenotic blood vessels may also explain why her blood pressure increased during pregnancy. Peripheral vascular resistance normally decreases during pregnancy leading to a decrease in blood pressure. Since she had stenotic vessels and could not decrease afterload, the BP increased secondary to the increase in blood volume that accompanies pregnancy. ${ }^{10}$

Although the use of regional anaesthesia has been cautioned against in the patient with TA, there are frequently other factors, such as pregnancy, that may make regional anaesthesia desirable. The authors feel that if attention is given to the maintenance of preload and that the BP changes are quickly treated, an epidural anaesthetic which can be titrated to effect is a good alternative to general anaesthesia in the patient with TA and can be used safely. However, spinal anaesthesia which is associated with a more profound decrease in preload should be avoided until further investigation has been performed in these patients.

Morphine sulphate was administered in the epidural space to avoid increases in blood pressure from postoperative pain. The patient was comfortable for $24 \mathrm{hrs}$ following the injection and did not require additional analgesics during this time.

In summary, we describe the first reported successful regional anaesthetic for a pregnant patient with severe TA presenting for Caesarean section. The advantages and disadvantages of both regional and general anaesthesia for this patient are discussed and the rationale for our choice of regional anaesthesia is presented.

\section{References}

1 de Jonge HJ, Knipscheer RJ, Weigel HM. Takayasu's or pulseless disease in pregnancy. Eur $\mathrm{J}$ Obstet Gynecol Reprod Biol 1983; 14: 241-9.

2 Ramanathan S, Gupta U, Chalon J, Turndorf $H$. Anesthetic considerations in Takayasu arteritis. Anesth Analg 1979; 58: 247-9.

3 Rozwadowski MA, Downing JW. Anesthetic management for nephrectomy in a child with Takayasu's arteritis and severe renovascular hypertension. S Afr Med J 1985; 67: 898-900.

4 Warner $M A$, Hughes $D R$, Messick $J M$. Anesthetic management of a patient with pulseless disease. Anesth Analg $1983 ; 62: 532-5$.
5 Wong VC, Wang RY, Tse TF. Pregnancy and Takayasu's arteritis. Am J Med 1983; 75: 597-601.

6 Dalen JE. Diseases of the aorta. In: Braunwald $\mathrm{E}$, Isselbacher KJ, Petersdorf RG, Wilson JD, Martin JB, Fauci AS (Eds.). Harrison's Principles of Internal Medicine. New York: McGraw Hill Book Co., 1987: 1037-40.

7 Parulkar GB, Kelkar MD. Nonspecific aortoarteritis. In: Rutherford RB (Ed.). Vascular Surgery (2nd Ed.). Philadelphia: W.B. Saunders Co., 1984: 731-44.

8 Ishikawa K, Matsuura S. Occlusive thromboaortopathy (Takayasu's disease) and pregnancy. Clinical course and management of 33 pregnancies and deliveries. Am J Cardiol 1982; 50: 1293-9.

9 Winn HN, Setaro JF, Mazor M, Reece A, Black HR, Hobbins JC. Severe Takayasu's arteritis in pregnancy: the role of central hemodynamic monitoring. Am J Obstet Gynecol 1988; 159: 1135-6.

10 Cheek TG, Gutsche BB. Maternal physiologic changes during pregnancy. In: Shnider SM, Levinson G (Eds.). Anesthesia for Obstetrics. Baltimore: Williams \& Wilkins, 1987: 3-13. 